\title{
Decadal variations of land surface temperature anomalies observed over the Tibetan Plateau by the Special Sensor Microwave Imager (SSM/I) from 1987 to 2008
}

\author{
Mhd. Suhyb Salama • Rogier Van der Velde • \\ Lei Zhong • Yaoming Ma • Matthew Ofwono • \\ Zhongbo Su
}

Received: 22 June 2010 / Accepted: 12 February 2012 / Published online: 7 March 2012

(C) The Author(s) 2012. This article is published with open access at Springerlink.com

\begin{abstract}
In this paper, we analyze the standardized anomalies of land surface temperature (LST) retrieved from the Special Sensor Microwave Imager (SSM/I) vertically polarized $37 \mathrm{GHz}\left(T_{B, 37 \mathrm{GHz}}^{v}\right)$ brightness temperature over the Tibetan Plateau for the period 1987 to 2008 . A radiative transfer model is used to derive LST from SSM/I $T_{B v, 37 \mathrm{GHz}}^{v}$, which is calibrated and validated using time series of field measured soil surface temperatures. Additional Plateau-scale verification is performed with monthly LST products from the Moderate Resolution Imaging Spectroradiometer, the Noah land surface model and air temperature measured by Chinese Meteorological Administration. Trend analysis shows that the annual and monthly standardized anomalies are increasing at an averaged rate of 0.5 decade $^{-1}$. The highest positive trends are noted over the central part of the Plateau, which is on average 0.80 decade $^{-1}$ with a maximum of 1.44 decade $^{-1}$. Conversely, a negative trend in the anomalies is found for the Taklamakan desert and the Himalayan foothills with a rate of $-0.27 \mathrm{decade}^{-1}$ and reaching a maximum of $-1.4 \mathrm{decade}^{-1}$. In addition, we find that LST anomaly trends on the Plateau are seasonally dependent and increase with the elevation. These observed trends are in agreement with previous studies conducted with in-situ measurements, which demonstrates the use of long-term earth observation programmes for climate studies as has also been articulated in the 2007 IPCC report.
\end{abstract}

M. S. Salama $(\bowtie) \cdot$ R. Van der Velde $\cdot$ M. Ofwono $\cdot$ Z. Su

ITC, University of Twente, PO Box 217, 7500 AE Enschede, The Netherlands

e-mail: salama@itc.nl

L. Zhong · Y. Ma

Institute of Tibetan Plateau Research, Chinese Academy of Science (ITP/CAS),

Beijing, People's Republic of China 


\section{Introduction}

Land-atmosphere interactions on the Tibetan Plateau modulates the atmospheric circulation over the Asian continent (Yanai and Wu 2006). This influences the development of weather systems (e.g. East Asian Monsoon) on a continental scale and has also an impact on other continents through large-scale tele-connections (Zhou et al. 2009). A change in the thermodynamic processes on the Plateau induced by global warming impacts our climate globally. Recent studies, evaluating longterm meteorological observations (e.g., Xu et al. 2006; Duan and Wu 2008) and reanalysis data sets (e.g., Yu et al. 2004), provide evidence for a southward shift of the upper level westerly jet stream, which weakens the East Asian summer monsoon. The effects of this shift in the atmospheric circulation and global warming are also noticed on the Plateau. For example, Liu et al. (2009) showed using meteorological observations in combination with satellite images that an expansion of two inland lakes by $27 \%$ can be associated with a $51.0 \mathrm{~mm}$ increase in the annual precipitation and a $0.41^{\circ} \mathrm{C}$ increase in the mean annual temperature. This warming of the Plateau has been confirmed by Zhao et al. (2004), in which the authors analyzed land surface and air temperature measurements from 119 stations distributed across the Tibetan Plateau.

Land surface temperature (LST) plays a critical role in the surface energy balance (Trenberth et al. 2007). Energy exchanges at the land-atmosphere interface are largely controlled by the difference between the skin and near-surface air temperature (Jin and Dickinson 2010). Hence, many international organizations have identified the need for long-term monitoring of the LST at large spatial coverage (King 1999). In response to this need and the recommendation of the Intergovernmental Panel on Climate Change (IPCC) for including remote sensing observations in climate studies (Houghton et al. 2001), we determine the LST from Special Sensor Microwave/Imager (SSM/I) collected over the Tibetan Plateau in period from 1987 to 2008 .

The SSM/I based LST products are calibrated/validated against in-situ measurements from a network of spatially distributed soil moisture/temperature stations. Monthly LST products from the Moderate Resolution Imaging Spectroradiometer (MODIS) and the Noah simulations (Ek et al. 2003) are utilized for a Plateauscale verification of the spatial distribution of SSM/I LST and LST trends over the years 2000 to 2006. A supporting long-term (1987-2003) verification of the SSM/I trends is performed against the proxy air temperature data set derived from daily measurements collected by the China Meteorological Administration (CMA). With the use of three independent data sets we evaluate the reliability of the SSM/I LST and can quantify with confidence the spatially distributed changes of LST anomalies across the Tibetan Plateau.

\section{Data sets}

\section{$2.1 \mathrm{SSM} / \mathrm{I}$}

$\mathrm{SSM} / \mathrm{I}$ is a microwave radiometer operating at four frequencies (19.4, 22.2, 37.0 and $85.5 \mathrm{GHz}$ ) onboard satellites supported through the defense meteorological 
satellite program (DMSP) since 1987; details can be found in Holinger (1991). SSM/I brightness temperatures $\left(T_{B}\right)$ are obtained from the National Snow and Ice Data Center (NSIDC) (Maslanik and Stroeve 2009), which are resampled to an EqualArea Scalable Earth (EASE)-Grid with an approximate $25-\mathrm{km}$ spatial resolution. Only the morning passes have been used in this study because then the top soil layer is typically in thermal equilibrium (Groisman and Genikhovich 1997). At this time of the day, also, the lower boundary layer approaches an equilibrium state reducing the impact of the atmosphere on $T_{B}$ yielding more reliable LST retrievals as compared to those obtained from the afternoon passes (Basist et al. 1998). In total 7,594 SSM/I morning acquisitions are available for the Tibetan Plateau from 1987 to 2008.

\subsection{Calibration/Validation data for SSM/I LST retrieval}

The data set used for calibration/validation of the LST retrieval method are obtained from a network centered on Naqu station $\left(91.89^{\circ} \mathrm{E}, 31.36^{\circ} \mathrm{N}\right.$, WSG84) that has been installed as a part of Global Energy and Water cycle Experiment (GEWEX), see the black flag in Fig. 1. The soil moisture/temperature network has been operational since 2006 and holds a three-year record that overlaps with the SSM/I data set. More details on the network can be found in Su et al. (2011).

The temperature records include readings, at time of the SSM/I overpass, from four stations measured at a soil depth of $2.5 \mathrm{~cm}\left(T_{2.5} \mathrm{~cm}\right)$. In total, we have 262 pairs of averaged $T_{2.5} \mathrm{~cm}$ and coinciding SSM/I brightness temperatures (matchups). The 262 matchups are divided into four groups ordered [1,2,3,4], whereby the odd groups are used for the calibration and the even groups for validation. As such, each set includes two non-consecutive periods. This procedure minimizes the annual trends and maximizes the range of the both matchup data sets.

\subsection{Data sources for Plateau-scale verification}

Additional data sets are used for verification of the LST values and trends as observed by SSM/I. These are:

1. MODIS LST night products;

2. Noah simulated LST product from the Global Land Data Assimilation System (GLDAS, Rodell et al. 2004);

3. Air temperature measurements from 49 CMA stations.

Fig. 1 The GTOPO30 Digital Elevation Model of the Tibetan Plateau (altitude $\geq 3,500 \mathrm{~m}$ ). The white triangles indicate the locations of the hydro-meteorological stations. The position of the Naqu station is indicated by the black flag

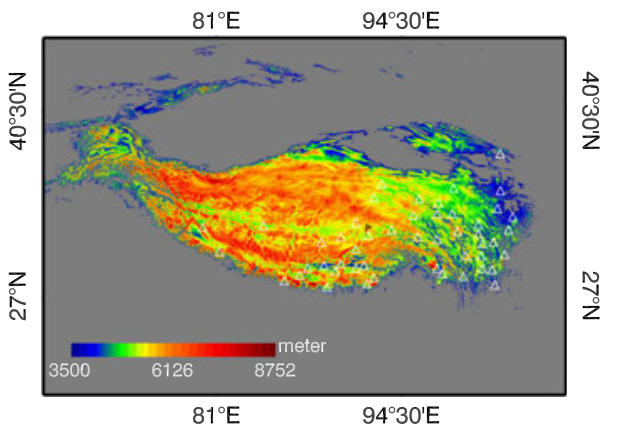


It should be noted that the MODIS LST, Noah-GLDAS LST and CMA in-situ air temperature data sets each relies a different, though scientifically-proven, method. Inherent differences between these three data sources and the SSM/I observed LST are, therefore, expected. At the same time, all four methods provide, independent from each other, information on the same LST state. As such, we utilize the MODIS LST, Noah-GLDAS LST and CMA air temperature data sets to support the spatial and temporal LST variability observed by SSM/I across the Tibetan Plateau.

\subsubsection{MODIS monthly LST product}

The MODIS/Terra V4 LST Global products (MOD11C3) are monthly composites, derived from the daily global products, and stored as clear-sky LST on a geographic grid at a $0.05^{\circ}$ resolution equivalent to about $5.6 \mathrm{~km}$. The V4 MOD11C3 products have an acquisition range from March-2000 until December-2006 (further details are available on: http://landval.gsfc.nasa.gov/ProductStatus.php). LST night products from the Terra MODIS sensor are chosen for this study due to the longer time series of Terra observations comparing to Aqua. Further, the night LST products are used because they are more accurate than the daily ones (Wang et al. 2008) and the night overpass matches better with the SSM/I observations.

\subsection{Noah-GLDAS LST product}

Simulated LST from the Noah model (Ek et al. 2003) are obtained from the Global Land Data Assimilation System (GLDAS, Rodell et al. 2004). Modeled data consist of monthly LST values simulated for seven years (2000-2006) to match the acquisition period of MODIS.

\subsubsection{CMA air temperature data}

In addition, the air temperature data set from China Meteorological Administration (CMA, http://cdc.cma.gov.cn/) is available for verifying SSM/I observed LST trends. The set, we use, consists of 17 years (1987 to 2003) of monthly 2-m air temperature values from 49 stations distributed across the Tibetan Plateau. The locations of these stations are shown as triangles in Fig. 1. The monthly air temperature values are derived from the daily averages provided by CMA that originate from four individual measurements taken each day nominally at 02:00, 08:00, 14:00, 20:00 Beijing Standard Time (BST).

\section{LST retrieval and validation}

The $T_{B}$ observed by microwave radiometers, such as SSM/I, can be computed with a semi-empirical emission model that accounts for radiative transfer processes along the soil-vegetation-atmosphere pathways (Kerr and Njoku 1990). According to this concept the p-polarized Top-Of-the-Atmosphere (TOA) $T_{B}, T_{B}^{p}$, can be computed as,

$$
\begin{aligned}
T_{B}^{p}= & T_{a}^{\uparrow}+\gamma_{a}\left(1-e_{s}^{p}\right) \gamma_{v}^{p}\left(T_{a}^{\downarrow}-\gamma_{a} T_{\mathrm{cos}}\right)+\gamma_{a} e_{s}^{p} \gamma_{v}^{p} T_{s} \\
& +\gamma_{a}\left(1-\omega^{p}\right)\left(1-\gamma_{v}^{p}\right)\left(1+\gamma_{v}^{p}-\gamma_{v}^{p} e_{s}^{p}\right) T_{v}
\end{aligned}
$$


where, $T_{a}^{\uparrow}$ and $T_{a}^{\downarrow}$ are respectively the up- and downward emitted atmospheric temperatures $(\mathrm{K}), \gamma_{a}$ and $\gamma_{v}$ are respectively the transmissivity of the atmosphere and the vegetation layer, $\omega$ is the single scattering albedo of the vegetation layer, $T_{s}$ and $T_{v}$ are respectively the soil and canopy temperatures $(\mathrm{K}), e_{s}$ is the soil surface emissivity, $T_{\cos }$ is the cosmic background (=2.7 K), and superscript and subscript $p$ indicates the polarization, which can either be horizontal, $h$, or vertical, $v$.

Pellarin et al. (2003) developed parametric relationships between radiative properties of the atmosphere $\left(T_{a}^{\uparrow}, T_{a}^{\downarrow}\right.$ and $\left.\gamma_{a}\right)$ and near-surface meteorological variables to correct for the atmosphere effects. However, we adopt in this study the $37 \mathrm{GHz}$ vertically polarized $T_{B}, T_{B, 37 \mathrm{GHz}}^{v}$, to estimate the LST. Colwell et al. (1983) has shown that for this frequency the atmospheric transmittance is high. Also, the disturbances of soil moisture at the vertically polarized $37 \mathrm{GHz}$ channel are limited because of the Brewster angle at the SSM/I view angles (Royer and Poirier 2010). This is confirmed by Holmes et al. (2009), whom has shown using radiative transfer simulations and observations that LST can be reliably estimated using a simple linear relationship based on the the $37 \mathrm{GHz}$ vertically polarized brightness temperature, $T_{B, 37 \mathrm{GHz}}^{v}$, of the form

$$
L S T=a T_{B, 37 \mathrm{GHz}}^{v}+b .
$$

where, $L S T$ is the land surface temperature, $a$ and $b$ are the regression coefficients that best describe the observations, i.e. matchup between SSM/I $T_{B, 37 \mathrm{GHz}}^{v}$ and measured $T_{2.5} \mathrm{~cm}$. The values of the coefficients $a$ and $b$ in Eq. 2 are derived from the matchup between Naqu measurements and SSM/I observations.

\subsection{Validation with Naqu data}

Figure 2a shows the linear relationship between observed $T_{B, 37 \mathrm{GHz}}^{v}$ and $T_{2.5 \mathrm{~cm}}$ for the matchup Naqu set. The coefficients of this linear function are fitted through data points of the calibration set using linear regression, which results in,

$$
T_{2.5 \mathrm{~cm}}=0.89 T_{B, 37 \mathrm{GHz}}^{v}+48.91 .
$$

The accuracy of Eq. 3 is evaluated using the validation set in Fig. 2b, which shows measured $T_{2.5} \mathrm{~cm}$ versus derived values. Goodness-of-fit statistical parameters of slope, intercept, $R^{2}$ and the mean absolute error (MAE, Willmott and Matsuura $2005)$ are estimated and shown on Fig. 2 b. The slope of derived values is very close to unity with an intercept of about $2.91 \mathrm{~K}$ and MAE less than $2.5 \mathrm{~K}$. The dynamic range in the validation set is about $25 \mathrm{~K}$. In a relative measure, the obtained intercept and MAE account for about $10 \%$ of the total measured range of soil temperature. Moreover, the relative error of individual data point (i.e. 1 - derived/measured) does not exceed $3.5 \%$.

The accuracy of Eq. 3 on monthly basis is further investigated by applying Eq. 3 to the monthly means of the $T_{B, 37 \mathrm{GHz}}^{v}$ and $T_{2.5 \mathrm{~cm}}$. These monthly values are computed for the entire data set. Table 1 shows the goodness-of-fit statistical parameters for the monthly data and for comparison also the fit parameters for the daily data are shown. The slope of derived monthly data is close to unity. Further, $R^{2}$ and MAE improved respectively from 0.86 and $2.96 \mathrm{~K}$ on a daily basis to 0.95 and $1.50 \mathrm{~K}$ on a monthly basis. A similar improvement has been reported by Basist et al. (1998), whom used monthly means to have a closer match between derived and measured values. The 
(a): Calibration/validation matchups

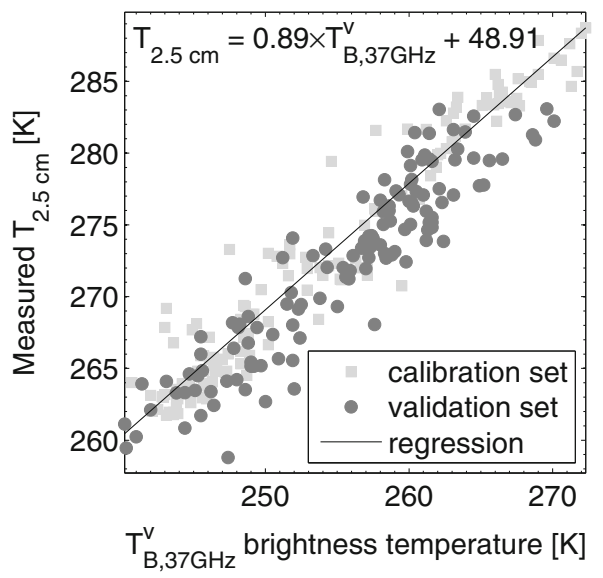

(b): Validation

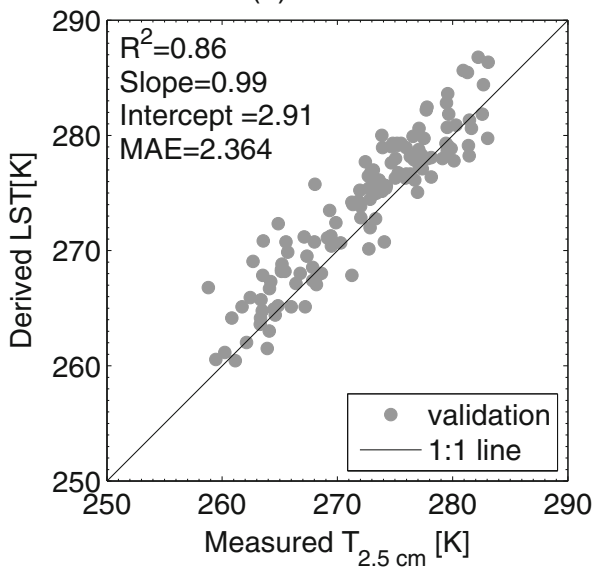

Fig. 2 a Measured $T_{2.5} \mathrm{~cm}$ versus SSM/I observed brightness temperature, $T_{B, 37 \mathrm{GHz}}^{v}$, for both calibration (light squares) and validation (dark circles) sets. Equation 3 is superimposed as a black line $; \mathbf{b}$ derived versus measured temperatures using the independent validation set

statistics presented in Table 1 show that Eq. 3 provides a reliable estimate of the $T_{2.5} \mathrm{~cm}$ on a monthly mean basis with MAE value of $1.50 \mathrm{~K}$ and a relative error of less than $1.5 \%$ for individual data points. In the following, we assume that the $T_{2.5} \mathrm{~cm}$ is representative for the LST, which is justified based on the fact that near dawn a thermal equilibrium prevails near the soil surface.

\subsection{Plateau-scale verification with MODIS and Noah-GLDAS}

Monthly standardized anomalies are computed from LST products of SSM/I, MODIS and Noah-GLDAS for a seven-year period (2000-2006) and compared with each other. The coefficient of determination, $R^{2}$, and MAE are selected for the evaluation. As we are comparing the anomalies, the systematic dissimilarities between model and observations LST values are eliminated, i.e. there is no need for a prior bias correction for LST values using, for example, CDF matching technique (Reichle and Koster 2004).

Figure 3 shows the coefficient of determination, $R^{2}$, and the MAE between derived LST from SSM/I and Noah-GLDAS in Fig. 3a and c, and between SSM/I and MODIS in Fig. 3b and d. SSM/I LST standardized anomalies agree with NoahGLDAS and MODIS with an average $R^{2}$ of $0.69 \pm 0.14$ and $0.83 \pm 0.18$, respectively.

Table 1 MAE and regression goodness-of-fit parameters between measured and derived soil temperatures for the monthly averaged matchup set and the daily validation set (a subset of the matchup set)

\begin{tabular}{lcllll}
\hline Matchup & $n$ & Slope & Intercept & MAE & $R^{2}$ \\
\hline Monthly & 17 & 0.94 & 16.41 & 1.50 & 0.95 \\
Daily & 132 & 0.99 & 2.91 & 2.36 & 0.86 \\
\hline
\end{tabular}

$n$ is the number of data points 


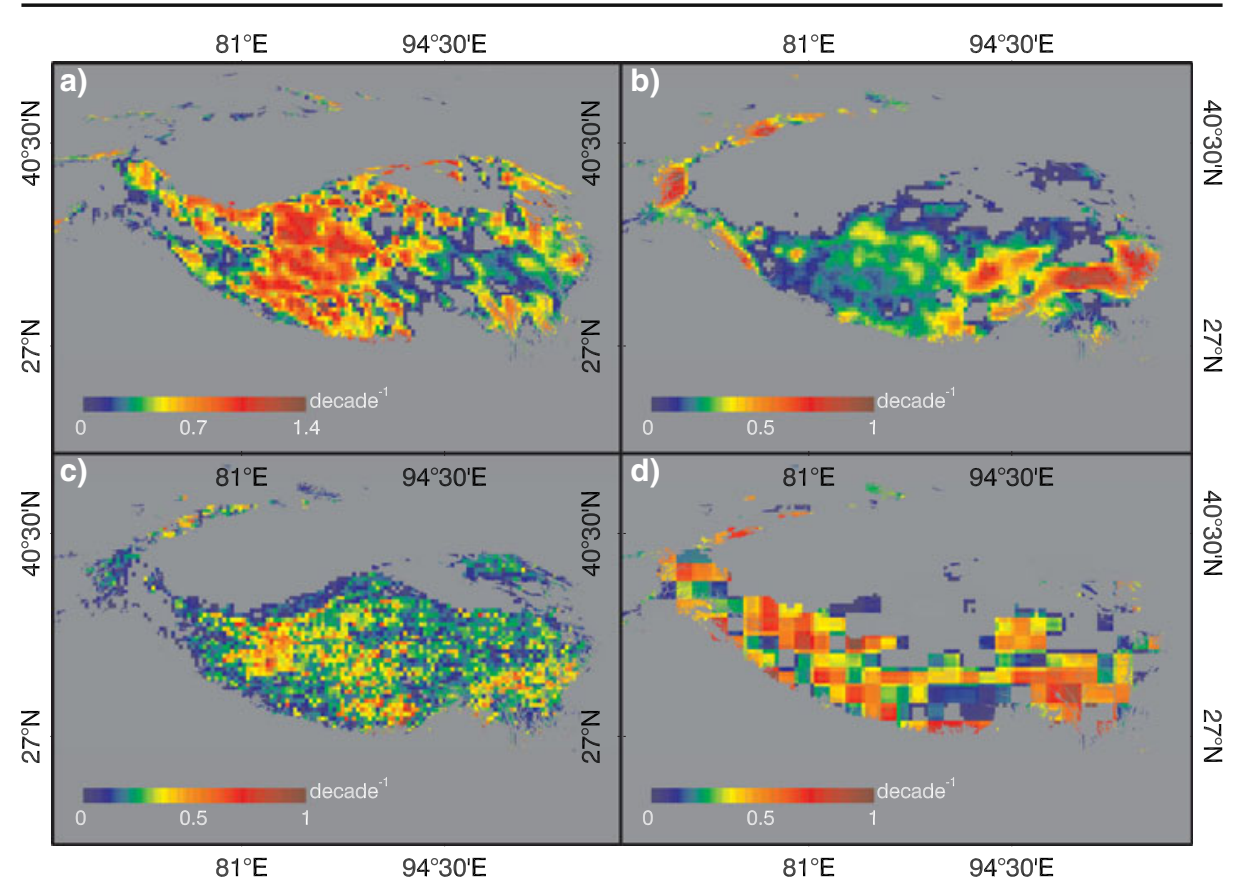

Fig. 3 Statistical measures of fit, $R^{2}$ and MAE, between LST anomalies of SSM/I and Noah-GLDAS (a, c) and SSM/I and MODIS (b and d)

The MAE, averaged over the entire Tibetan Plateau, does not exceed $0.45 \pm 0.12$ for Noah-GLDAS and $0.3 \pm 0.15$ for MODIS. The observed agreement between thermal (MODIS) and passive microwave (SSM/I) LST products is in line with previous studies. For instance, Parinussa et al. (2008) observed a similar agreement between LST products of MODIS and the results of Eq. 2 when applied to SSM/I over the National Airborne Field Experiment research sites in the western part of the Murrumbidgee catchment, Australia.

The agreements with SSM/I is for both Noah-GLDAS and MODIS strongest in the central part of the Plateau, whereas a weaker correspondence is noted in the eastern and north western parts. The discrepancy between Noah-GLDAS and earth observation (SSM/I and MODIS) can be attributed to uncertainties in forcing fields and imperfect land parameterizations that may lead to considerable drifts in the modeled land surface temperature (Reichle et al. 2010).

\section{Trend analysis of LST anomaly}

\subsection{SSM/I}

Equation 3 is applied to derive LST from the SSM/I $T_{B, 37 \mathrm{GHz}}^{v}$ acquired between 1987 and 2008 over the Tibetan Plateau. Annual and monthly standardized anomalies are computed from these LST products using the mean $(\mu)$ and variance $\left(\sigma^{2}\right)$ calculated among the years and the individual months within the period 1987-2008, 
as $(L S T-\mu) / \sigma$. Following Liu and Chen (2000), the trend is computed by fitting a linear regression model to LST anomalies over time at each pixel. We use the resulting slope as a measure for trend of the LST anomaly. A $t$-test is performed to validate the significance of the obtained trends. The results of the $t$-test, not presented here, confirm that all trends are significantly different from zero.

Figure 4 shows the trend of LST annual anomalies for the Tibetan Plateau and the surrounding areas. Trends of LST anomalies vary from -1.5 decade $^{-1}$ to 1.5 decade $^{-1}$. The decrease appears in the low elevated arid areas of the Taklamakan desert and at the foothills of the Himalayas, while the increase is prominent over the Tibetan Plateau. The LST anomaly trend of the Taklamakan desert and the Himalayan foothills are on average $-0.27 \pm 0.23$ decade $^{-1}$ and reaches a minimum rate of -1.4 decade $^{-1}$. The negative LST anomaly trends observed at the foothills of the Himalayas is explained by the advection of moisture, which is associated by an increased cloud coverage and rainfall in the southern region (Shrestha et al. 1999). On the other hand, the negative trend of the Taklamakan desert is explained by a reduction in the soil heat capacity. It is well-known that wet soils are able to store more heat than a dry soil (e.g., Peters-Lidard et al. 1998; Van der Velde et al. 2009). As warming leads, in general, to more evaporation during daytime, the reduced moisture content causes enhanced release of soil heat at night resulting in lower morning temperatures. In this view, the negative trend observed over the arid Taklamakan could be indicative for a further water depletion and desertification.

The trend of LST anomalies, Fig. 4, is increasing with an average rate of $0.5 \pm$ 0.28 decade $^{-1}$. The positive trends are highest at the central part of the Plateau, which is on average $0.8 \pm 0.021$ decade $^{-1}$ and reaches a maximum of 1.44 decade $^{-1}$.

\subsection{Verification}

These positive trends of LST anomalies over the Tibetan Plateau, obtained from SSM/I time series, are verified with MODIS and Noah-GLDAS LST products for the short period (2000-2006) of MODIS acquisitions. It should, however, be noted that the trends for the period 2000-2006 (in Fig. 5b) are not representative for the LST trends observed by SSM/I from 1987-2008 (Fig. 5a). This can be explained by interannual cooling-warming cycles. In fact, Zhao et al. (2004) show through analysis of a 30-year series of in-situ measurements that the Tibetan land surface exhibits

Fig. 4 Trends of LST anomalies per decade, derived from the 1987-2008 SSM/I data set for Tibet and surrounding areas: the scenery of SSM/I images

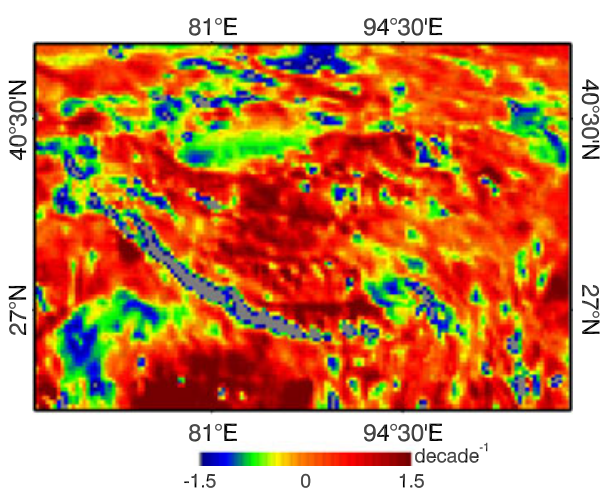




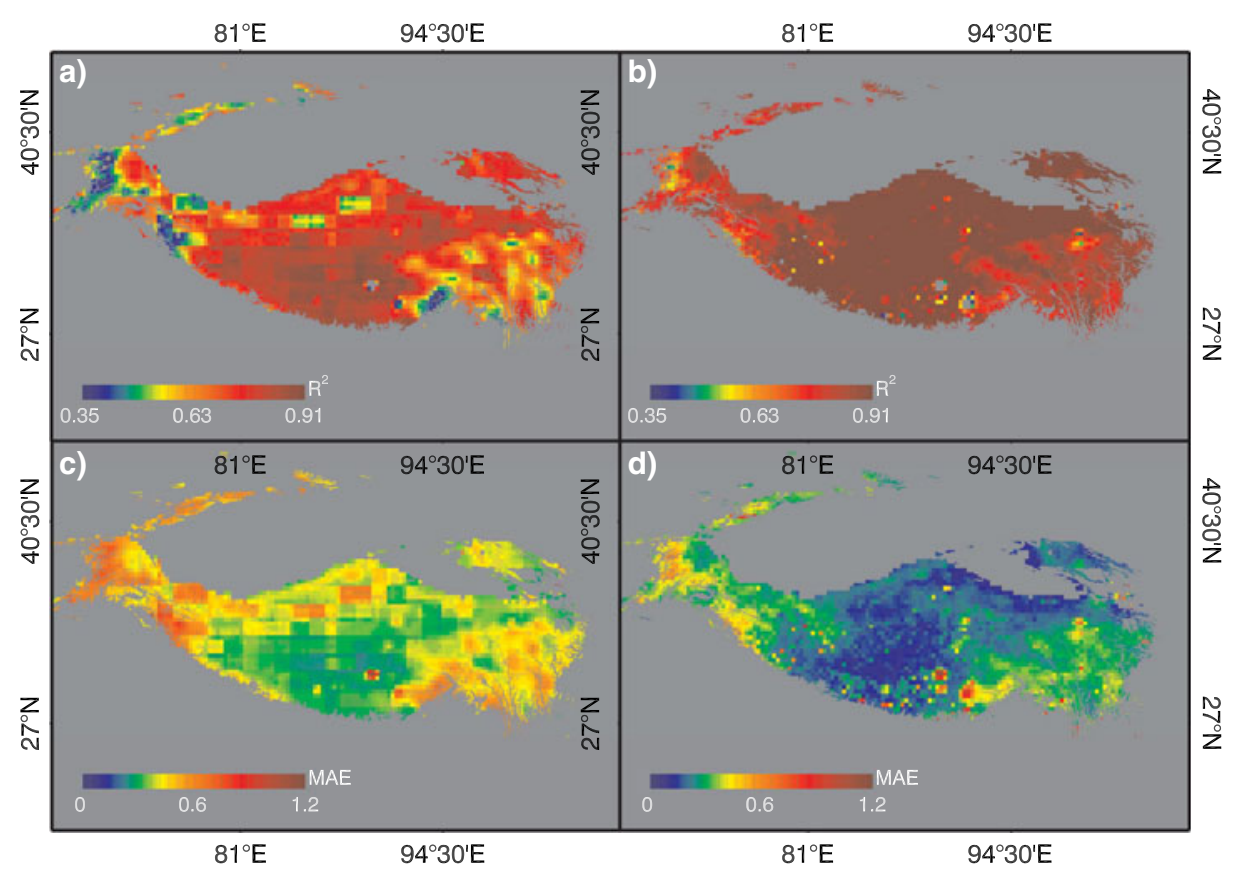

Fig. 5 Positive decadal trends of LST anomalies for the period between 1987 and 2008 derived from SSM/I (a); and for the period between 2000 and 2006 derived from b SSM/I, c MODIS and d NoahGLDAS

cycles with prolonged warming and cooling with a typical period of eight years. From this perspective, the time span of MODIS and Noah-GLDAS LST anomalies is somewhat short. However, both do show positive trends similar to those observed by SSM/I in the central and southern parts of the Plateau.

The overlap of the CMA air temperature data set with SSM/I LST is larger (1987-2003) and can be used as a proxy to verify the SSM/I LST magnitude and trends with more certainty. Figure 6 shows the SSM/I derived monthly LST values and the monthly air temperatures averaged for the 49 CMA stations plot-

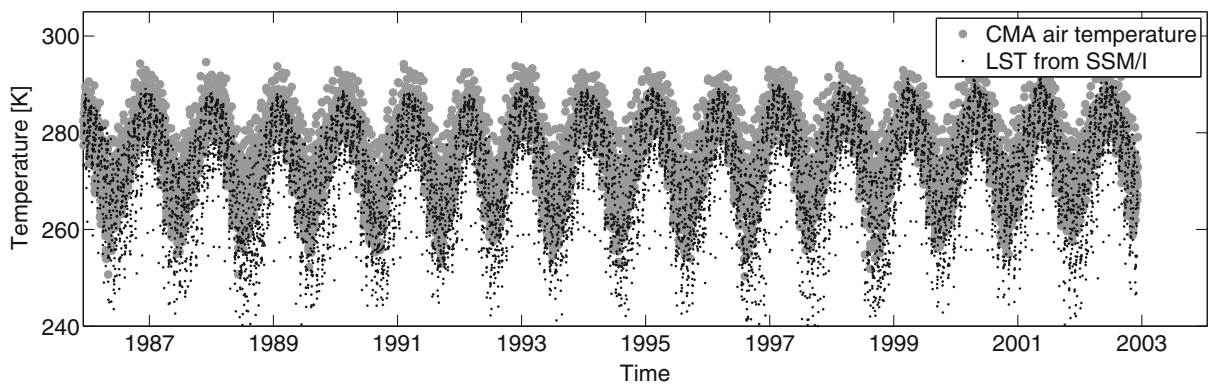

Fig. 6 SSM/I derived LST values superimposed on measured air temperature from the 49 CMA hydrometeorological stations between 1987 and 2003 
ted against time. Air temperature (averaged over all 49 stations) has increased by $0.275 \pm 0.0216 \mathrm{~K}$. decade $^{-1}$, whereas the SSM/I LST has increased by $0.78 \pm$ $0.0631 \mathrm{~K} . \mathrm{decade}^{-1}$. These trend values are consistent with observations made by Zhao et al. (2004) and Mildrexler et al. (2011). Both studies show that the LST is closely related to air temperature, but has a faster rate of increase.

\subsection{Altitudinal and seasonal dependence}

A more pronounced positive trend at high elevations than at low elevations can be observed when the LST anomalies trend is plotted against the GTOPO30 Digital Elevation Model (DEM) altitude. Figure 7 shows that the trend increases about 0.127 decade $^{-1}$ per $\mathrm{km}$. Apparently, the high elevated regions on the Plateau exhibit an amplified regional LST anomaly trend. Giorgi et al. (1997) found a similar dependency of the warming on the altitude within the output of a climate model. They attributed this amplified warming at higher elevations to a reduction in snow and glaciers, which decreases the surface albedo and increases the solar radiation absorbed by the land surface. Recently, Qin et al. (2009) have confirmed the altitudinal dependence of LST trends using MODIS products over the Tibetan Plateau.

The seasonal LST anomaly trends are influenced by the dynamics of the summer monsoon (see for example, Oku et al. 2006). Figure 8 shows a cross-section at $32^{\circ}$ $\mathrm{N}$ with the derived trend of LST anomalies for each month. Trends in western and central parts show a very distinct intense increase during the monsoon season. The positive trend in the other months is higher at the onset of the Asian summer monsoon ( $\sim$ April-May) with a rate of about 1.4 decade $^{-1}$. This positive trend decreases gradually up to September where it suddenly drops as the winter sets in. The eastern Tibet behaves differently. A slight increase is noted during the winters and the increase saddle throughout the monsoon is much shortened. This contrast between the western-central and the eastern parts is in accordance with previous reports. For example, Yanai and Wu (2006) described the Tibetan Plateau as a heat source for the atmosphere in the summer with exception of the south eastern part.

Fig. 7 Trends of LST anomalies observed over the Tibetan Plateau versus elevation. The black line is the linear regression of the LST trend as function of elevation

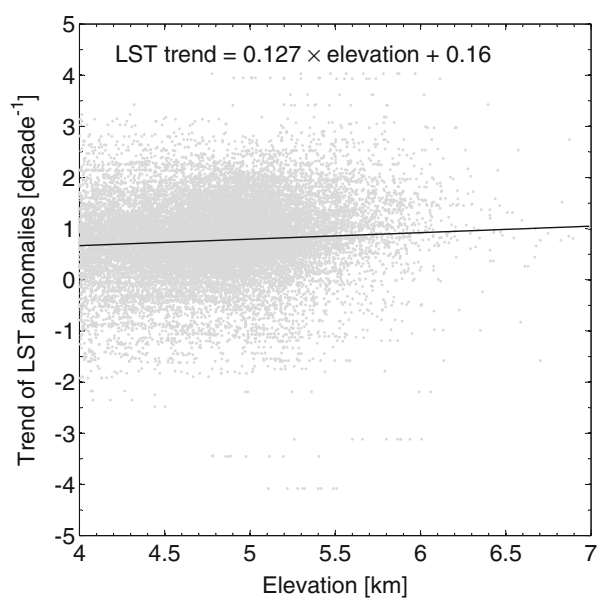




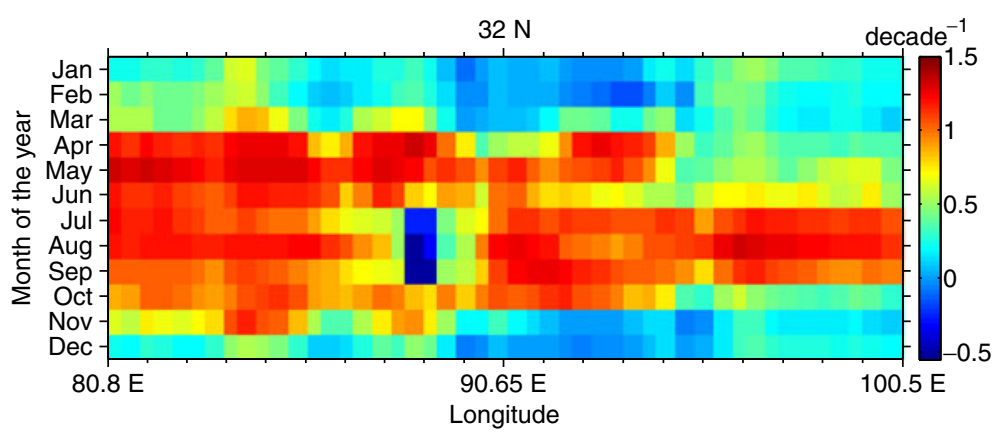

Fig. 8 A cross section at $32^{\circ} \mathrm{N}$ in SSM/I climatology trends of Tibetan Plateau LST standardized anomalies

Typically, south eastern Tibet receives the largest amount of precipitation (Zhao et al. 2004) and, as such, provides environments that are able to sustain denser vegetation covers than the prairie grasslands and alpine desert in central and western Tibet. Wen et al. (2004) and Zhong et al. (2010) have also demonstrated the effect of vegetation dynamics on temperature variations of the Tibetan Plateau.

The dip in the trend of LST anomalies at $\sim 90.22^{\circ} \mathrm{E}$ is explained by two hydrometeorological processes: (1) the formation of water ponds during the rainy monsoon season; (2) the growth of water reservoirs on the Plateau caused by snow and glacier melting due to the general warming.

\section{Conclusions}

In this paper, we evaluate long term land surface temperature trends observed over the Tibetan Plateau by SSM/I. A linear relationship with the SSM/I $T_{B, 37 \mathrm{GHz}}^{v}$ as input, calibrated and validated for the Tibetan Plateau, is used for the LST retrieval. Trends of the annual and monthly LST anomalies are derived by fitting a regression model to the anomaly over time at each pixel. The trends are established with the SSM/I observed LST collected from 1987 to 2008. Shorter time series of monthly MODIS LST (2000-2006), Noah LST simulations (2000-2006) and 2-m air temperature measurements (1987-2003) all three independently confirm this observation.

The overall analysis of 1987-2008 SSM/I data shows that LST anomaly in the central part of the Tibet Plateau is increasing at an average rate of 0.8 decade $^{-1}$. On the other hand, the Himalayan foothills and the Taklamakan desert display over this period a negative rate of -0.27 decade $^{-1}$, on average. The strongest increase in LST anomaly on the western and central part of the Plateau is noted at the onset (April-May) of the monsoon. In addition, the areas located at a higher elevation exhibit an accelerated positive trend over the low elevated regions by about 0.127 decade $^{-1} \mathrm{~km}^{-1}$.

The LST changes observed on the Tibetan Plateau has and will have profound implications on the atmospheric circulation at continental and even global scale. Wu et al. (2007) and Song et al. (2009), among others, suggest that the warming of the Tibetan Plateau contributes directly to the South Asian High (SAH) shift, which may 
further alter monsoon precipitation. Furthermore, the warming of Tibetan Plateau surface also impacts the carbon cycle as it accelerates permafrost melting resulting in the release of additional carbon (Fily et al. 2003).

Acknowledgements The National Meteorological Information Centre in China (CMA, http://cdc. cma.gov.cn/) is acknowledged for providing data from the hydrometeorlogical stations distributed over the Tibet.

The MODIS L3 data are obtained through the online Data Pool at the NASA Land Processes Distributed Active Archive Center (LP DAAC), USGS/Earth Resources Observation and Science (EROS) Center, Sioux Falls, South Dakota (http://lpdaac.usgs.gov/get_data).

Open Access This article is distributed under the terms of the Creative Commons Attribution License which permits any use, distribution, and reproduction in any medium, provided the original author(s) and the source are credited.

\section{References}

Basist A, Grody NC, Peterson TC, Williams CN (1998) Using the special sensor microwave/imager to monitor land surface temperatures, wetness, and snow cover. J Appl Meteorol 37:888-911

Colwell R, Simonett D, Ulaby F (eds) (1983) Manual of remote sensing, vol 2. Interpretation and applications, 2nd edn. Am. Soc. of Photogramm., Falls Church, VA

Duan A, Wu G (2008) Weakening trend in the atmospheric heat source over the Tibetan Plateau during recent decades. Part I: observations. J Clim 21(13):3149-3164

Ek MB, Mitchell KE, Lin Y, Rogers E, Grummann P, Koren V, Gayno G, Tarpley JD (2003) Implementation of Noah land surface model advances in the National Centers for Environmental Prediction operational mesoscale eta model. J Geophys Res 108:8851

Fily M, Royer A, Goita K, Prigent C (2003) A simple retrieval method for land surface temperature and fraction of water surface determination from satellite microwave brightness temperatures in sub-arctic areas. Remote Sens Environ 85:328-338

Giorgi F, Hurrell J, Marinucci M, Beniston M (1997) Elevation dependency of the surface climate change signal: a model study. J Clim 10:288-296

Groisman PY, Genikhovich EL (1997) Assessing surface-atmosphere interactions using former Soviet Union standard meteorological network data. Part I: method. J Clim 10:2154-2183

Holinger J (1991) DMSP special sensor microwave/imager calibration/validation. Final report, vol II. Naval Research Laboratory, Washington, DC

Holmes TR, de Jeu RA, Owe M, Dolman AJ (2009) Land surface temperature from Ka band (37 $\mathrm{GHz}$ ) passive microwave observations. J Geophys Res 114:D04113

Houghton JT, Ding Y, Griggs DJ, Noguer M, Van der Linden PJ, Xiausu D (2001) Climate change 2001: the scientific basis. Cambridge University Press, Cambridge, MA

Jin M, Dickinson RE (2010) Land surface skin temperature climatology: benefitting from the strengths of satellite observations. Environ Res Lett 5:044004

Kerr YH, Njoku EG (1990) A semiempirical model for interpreting microwave emission from semiarid land surfaces as seen from space. IEEE Trans Geosci Remote 28(3):384-393

King MD (1999) EOS science plan: the state of science in the EOS program. NASA, Washington, DC

Liu X, Chen B (2000) Climatic warming in the Tibetan Plateau during recent decades. Int J Climatol 20:1729-1742

Liu J, Wang S, Yu S, Yang D, Zhang L (2009) Climate warming and growth of high-elevation inland lakes on the Tibetan Plateau. Glob Planet Chang 67(3-4):209-217

Maslanik J, Stroeve J (2009) DMSP SSM/I daily polar gridded brightness temperatures, 1987-2008. Digital media. National Snow and Ice Data Center, Boulder, CO

Mildrexler DJ, Zhao M, Running SW (2011) A global comparison between station air temperatures and MODIS land surface temperatures reveals the cooling role of forests. J Geophys Res 116(G03025):1-15

Oku Y, Ishikawa H, Haginoya S, Ma Y (2006) Recent trends in land surface temperature on the Tibetan Plateau. J Climatol 19(12):2995-3003

Pellarin T, Wigneron J, Calvet J, Waldteufel P (2003) Global soil moisture retrieval from a synthetic L-band brightness temperature data set. J Geophys Res 108(D12):4364 
Parinussa RM, de Jeu RA, Holmes TR, Walker JP (2008) Comparison of microwave and infrared land surface temperature products over the NAFE'06 research sites. IEEE Geosci Remote Lett 5(4):783-787

Peters-Lidard CD, Blackburn E, Liang X, Wood EF (1998) The effect of soil thermal conductivity parameterization on surface energy fluxes and temperatures. J Atmos Sci 55(7):1209-1224

Qin J, Yang K, Liang S, Guo Z (2009) The altitudinal dependence of recent rapid warming over the Tibetan Plateau. Clim Change 97:321-327

Reichle RH, Koster RD (2004) Bias reduction in short records of satellite soil moisture. Geophys Res Lett 31(L19501):1-4

Reichle RH, Kumar SV, Mahanama SP, Koster RD, Liu Q (2010) Assimilation od satellite-derived skin temperature observations into land surface models. J Hydrometeorol 11(5):1103-1122

Rodell M, Houser PR, Jambor U, Gottschalck J, Mitchell K, Meng C-J, Arsenault K, Cosgrove B, Radakovich J, Bosilovich M, Entin JK, Walker JP, Lohmann D, Toll D (2004) The global land data assimilation system. Bull Am Meteorol Soc 85(3):381-394

Royer A, Poirier S (2010) Surface temperature spatial and temporal variations in North America from homogenized satellite SMMR-SSM/I microwave measurements and reanalysis for 19792008. J Geophys Res 115:D08110

Shrestha AB, Wake CP, Mayewski PA, Dibb JE (1999) Maximum temperature trends in the Himalaya and its vicinity: an analysis based on temperature records from Nepal for the period 1971-1994. J Clim 12(9):2775-2786

Song J-H, Kang H-S, Byun Y-H, Hong S-Y (2009) Effects of the Tibetan Plateau on the Asian summer monsoon: a numerical case study using a regional climate model. Int $\mathrm{J}$ Climatol. doi:10.1002/joc. 1906

Su Z, Wen J, Dente L, van der Velde R, Wang L, Ma Y, Yang K, Hu Z (2011) The Tibetan Plateau observatory of Plateau scale soil moisture and soil temperature, Tibet - Obs, for quantifying uncertainties in coarse resolution satellite and model products. Hydrol Earth Syst Sci 15(7): 2303-2016

Trenberth K et al (2007) Observations: surface and atmospheric climate change. In: Climate change 2007: the physical science basis. Contribution of working group I to the fourth assessment report of the Intergovernmental Panel on Climate Change. Cambridge University Press, Cambridge, UK and New York, NY, USA

Van der Velde R, Su Z, Ek M, Rodell M, Ma Y (2009) Influence of thermodynamic soil and vegetation parameterizations on the simulation of soil temperature states and surface fluxes by the Noah LSM over a Tibetan Plateau site. Hydrol Earth Syst Sci 13(6):759-777

Wang W, Liang S, Meyers T (2008) Validating MODIS land surface temperature products using long-term nighttime ground measurements. Remote Sens Environ 112:623-635

Wen J, Su Z, Ma Y (2004) Reconstruction of a cloud-free vegetation index time series for the Tibetan Plateau. Mt Res Dev 24(4):348-353

Willmott CJ, Matsuura K (2005) Advantages of the mean absolute error (MAE) over the root mean square error (RMSE) in assessing average model performance. Clim Res 30:79-82

Wu GX, Liu YM, Wang TM, Wan RJ, Liu X, Li WP, Wang ZZ, Zhang Q, Duan AM, Liang XY (2007) The influence of mechanical and thermal forcing by the Tibetan Plateau on Asian climate. J Hydrometeorol 8(4):770-789

Xu M, Chang CP, Fu CB, Qi Y, Robock A, Robinson D, Zhang HM (2006) Steady decline of East Asian monsoon winds, 1969-2000: evidence from direct ground measurements of wind speed. J Geophys Res 111(D24111):8. doi:10.1029/2006JD007337

Yanai M, Wu G-X (2006) Effects of the Tibetan Plateau. In: Wan B (ed) The Asian monsoon. Springer, Berlin, pp 514-549

Yu RC, Wang B, Zhou TJ (2004) Tropospheric cooling and summer monsoon weakening trend over East Asia. Geophys Res Lett 31(L22212):4. doi:10.1029/2004GL021270

Zhao L, Ping C-L, Yang D, Cheng G, Ding Y, Liu S (2004) Changes of climate and seasonally frozen ground over the past 30 years in Qinghai-Xizang (Tibetan) Plateau, China. Glob Planet Change 43(1-2):19-31

Zhong L, Ma Y, Salama MS, Su Z (2010) Assessment of vegetation dynamics and their response to variations in precipitation and temperature in the Tibetan Plateau. Clim. Change 103(3-4):519535

Zhou X, Zhao P, Chen J, Chen L, Li W (2009) Impacts of thermodynamic processes over the Tibetan Plateau on the Northern hemispheric climate. Sci China Ser D: Earth Sci 52(11):1679-1693 